\title{
Sensor Inferencial Neural para Determinação da Massa de um Produto em um Secador Agrícola
}

\author{
Diêgo dos Santos Carneiro *, Agnaldo José da Rocha Reis* \\ Silvia Grasiella Moreira Almeida **, Cristiano Lúcio Cardoso Rodrigues ** \\ * Departamento de Engenharia de Controle e Automação \\ (DECAT), Universidade Federal de Ouro Preto, MG, Brasil (emails: \\ d13go.santos@hotmail.com; reis@ufop.edu.br). \\ ** Coordenadoria de Automação Industrial (CODAAUT), Instituto \\ Federal de Minas Gerais, Ouro Preto, $M G$, Brasil (emails: \\ silvia.almeida@ifmg.edu.br; cristiano.rodrigues@ifmg.edu.br).
}

\begin{abstract}
An automatic drying system for agricultural products is located in the Electronic Instrumentation Laboratory of the Federal Institute of Minas Gerais, Campus of Ouro Preto (IFMG-OP). For performing the drying process, the air must be heated and blown in order to come into contact with the product of interest (e.g. corn). The measurement of the water content of the product is performed by weighing it over time with the use of S-type load cells. In this work, an Artificial Neural Network (ANN) was trained to assist in the calibration of the weighing system of the agricultural dryer. The outputs of a set of load cells (given in milivolts) were measured after the insertion of known masses of dry corn into the system and the drying air flow variation for each mass considered. The measured voltages and airflows were used as inputs to the ANN, while the reference masses considered were placed as outputs for the network.

Resumo: Um sistema automático de secagem de produtos agrícolas se encontra nas dependências do Laboratório de Instrumentação Eletrônica do Instituto Federal de Minas Gerais, Campus de Ouro Preto (IFMG-OP). Para a realização do processo de secagem, o ar tem que ser aquecido e soprado de modo a entrar em contato com o produto de interesse (e.g. milho). A medição do teor de água do produto é realizada pesando-o ao longo do tempo com o emprego de células de carga do tipo S. Neste trabalho, treinou-se uma Rede Neural Artificial (RNA) para auxiliar na calibração do sistema de pesagem do secador de produtos agrícolas supracitado. As saídas de um conjunto de células de carga (dadas em milivolts) foram medidas após a inserção de massas conhecidas de milho seco no sistema e a variação do fluxo de ar de secagem para cada massa considerada. As tensões e os fluxos de ar medidos foram usados como entradas para a RNA, enquanto que as massas de referência utilizadas foram colocadas como saídas da rede.
\end{abstract}

Keywords: Neural network, Load Cells, Airflow, Calibration, Drying

Palavras-chaves: Rede neural, Células de carga, Fluxo de ar, Calibração, Secagem

\section{INTRODUÇÃO}

O processo de secagem tem por objetivo manter a qualidade dos produtos após a colheita, pois devido aos altos teores de água no alimento, há um maior aparecimento de fungos e insetos, deteriorando a qualidade dos grãos e frutos armazenados na colheita (Corrêa et al., 2010). A secagem é a remoção parcial da água contida nos produtos agrícolas, para que esses atinjam um teor de água que permita a armazenagem durante um longo tempo, protegendo-os contra degradação e aumentando a vida útil do produto (SILVA et al., 2015).

Para se obter teores de água adequados e boa eficiência energética no processo de secagem, é necessário mensurar e controlar as condições ambientais sob as quais o produto está submetido (e.g. temperatura e fluxo do ar de secagem). Além disso, o teor de água do produto pode ser obtido utilizando-se a base úmida (b.u) ou base seca do produto (b.s) (SILVA, 2001). O cálculo do teor de água em base úmida se dá em função da variação da massa de produto ao longo do tempo e pode ser descrito pela equação 1:

$$
M_{t}=1-\frac{m_{0}}{m_{t}}\left(1-M_{0}\right)
$$

Em que $M_{t}$ é o teor de água (decimal) ao longo do tempo, $m_{0}$ é a massa inicial do produto, $m_{t}$ é a massa ao longo do tempo e $M_{0}$ é o teor de água inicial do produto.

Para determinar os teores de água e consequentemente as taxas de secagem do produto, a metodologia geralmente utilizada para coletar dados baseia-se no registro das perdas de massa ocorridas em uma amostra durante o processo de secagem. Tais registros, muitas vezes são 
obtidos retirando-se a amostra do secador, levando-a até um dispositivo de pesagem e armazenando os valores medidos em planilhas [Palacin et al. (2005)]. Porém, de acordo com Monte et al. (2008), essa operação gera erros na determinação das taxas de secagem, uma vez que há uma interrupção do processo de secagem e consequente perda de uma certa quantia da amostra ao se realizar a pesagem.

Uma das formas de se obter os valores das massas é utilizando-se células de carga que, de acordo com Technologies (2012), são dispositivos baseados em uma Ponte de Wheatstone (PW), em que esforços de tração ou compressão nesses elementos geram uma tensão elétrica proporcional ao esforço sofrido.

Por meio das células de carga com PW, normalmente são obtidas curvas lineares que relacionam a tensão de saída à massa do produto. Tais curvas resultam em equações de primeiro grau, nas quais a massa é uma função linear da tensão elétrica das células de carga, resultando em uma curva de calibração específica para cada célula do sistema. Sendo a célula de carga um transdutor capaz de fornecer uma tensão proporcional à massa que suporta, é possível integrá-la a sistemas de aquisição de dados. Assim, a massa atual medida pode ser calculada a partir da tensão medida.

No secador abordado neste trabalho, há uma forte influência na pesagem devido ao esforço causado pela inserção de um fluxo de ar controlado que é insuflado através de bandejas nas quais o produto está inserido (ver Fig.1). Isso causa alterações na leitura das tensões das células de carga, agindo como uma força contrária à exercida pela massa do produto. Esse efeito resulta em valores de massa medidos aquém dos valores reais, uma vez que a curva de calibração padrão desconsidera a influência de outros fatores senão a própria massa do produto.

O modelo de sistema de pesagem elaborado por Rodrigues et al. (2011) consiste na obtenção de curvas de calibração para diferentes fluxos de ar. Este método, porém, não é capaz de calcular as curvas de massa x tensão para um número maior de fluxos de ar de secagem, necessitando uma nova calibração para cada fluxo de interesse. A necessidade de uma calibração para cada fluxo torna a utilização do secador mais complexa e onerosa.

Uma outra abordagem para contornar esse problema é desligar o sistema de ventilação em intervalos de tempo prédefinidos e então realizar a aquisição de dados das massas, tal como feito por Carneiro (2019). Esse procedimento é factível, pois a curva padrão de calibração é obtida para fluxo de ar nulo. Desse modo, a tensão obtida será em função somente da massa do produto. Entretanto, isso causa rápidas variações na temperatura e no fluxo de secagem, uma vez que ao se desligar a ventilação, a temperatura sobe e o fluxo é nulo. Já ao se religar, a temperatura cai e o fluxo aumenta rapidamente. Portanto, mesmo que o controle do secador seja robusto, o sistema terá oscilações constantes, interferindo no processo de secagem.

Assim, a proposta deste trabalho é encontrar um modelo baseado em redes neurais artificiais capaz de calcular a massa do produto medida por uma célula de carga, levando em consideração o fluxo desejado e a tensão lida, sem a necessidade de calibrações adicionais quando houver variações de fluxo e descartando a necessidade de se desligar o sistema para realizar a aquisição de dados de massa.

Este artigo está organizado como se segue. A Seção 2 apresenta em detalhes o protótipo do sistema de secagem. Já a Seção 3 trata dos métodos de pesagem. A Metodologia empregada é assunto da Seção 4 e os resultados e sua discussão são assuntos da Seção 5. As principais conclusões e sugestões de trabalhos futuros estão na Seção 6 e uma lista das Referências consultadas aparece em seguida.

\section{O PROTÓTIPO DO SISTEMA DE SECAGEM}

O protótipo do secador cuja massa deseja-se medir permite a realização de testes de secagem (Fig.1).

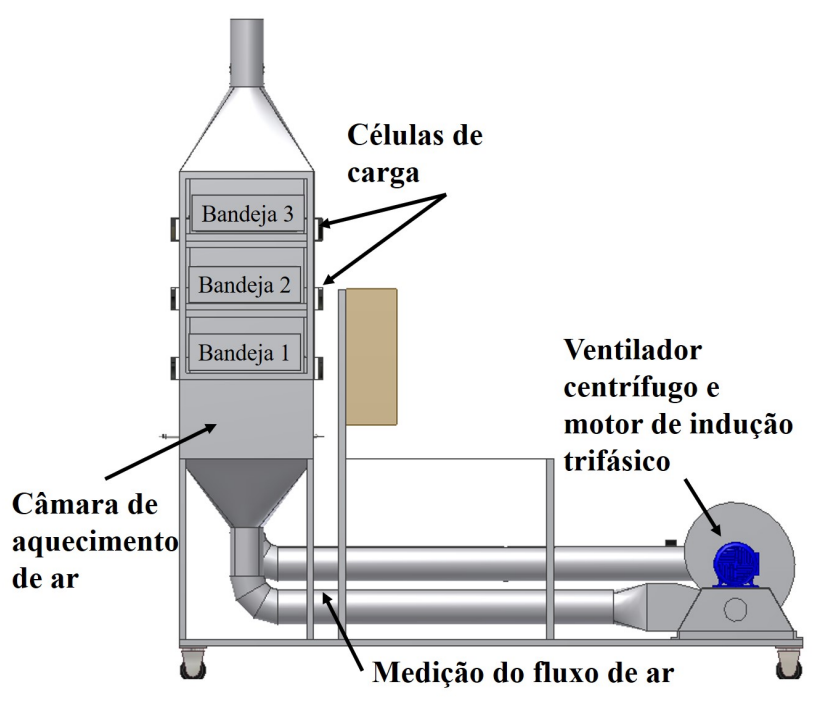

Figura 1. Desenho do protótipo do sistema de secagem (Fonte: Rodrigues et al. (2011) - Adaptada)

Há três bandejas apoiadas em uma base fixa com duas células de carga, cada uma em uma lateral da estrutura, em que são colocadas amostras de produtos a serem secos e os teores de água do produto são calculados por meio das massas lidas. $\mathrm{O}$ ar ambiente é inserido no sistema com a abertura de uma válvula borboleta controlada por um servo-motor. O transporte do ar pelo duto de ventilação é possibilitado por um ventilador centrífugo acoplado a um motor de indução trifásico. Ao passar pela câmara de aquecimento, o ar de secagem é aquecido e passa através das bandejas de produto realizando a secagem. O ar quente sai do sistema por meio da abertura de uma válvula de exaustão.

\section{MÉTODOS DE PESAGEM}

Os métodos de pesagem do produto podem influenciar na exatidão dos dados de secagem. Alguns desses métodos são listados a seguir.

- Retirada do produto para medição externa da massa, com dados em planilhas (Palacin et al., 2005).

- Sistema automático de pesagem utilizando células de carga:

Utilizando uma equação linear de massa x tensão (Monte et al., 2008); 
- Utilizando equações lineares de massa x tensão para alguns fluxos de ar (Rodrigues et al., 2011); - Utilizando uma equação linear de massa x tensão, desligando - se o sistema de ventilação na aquisição da massa (Carneiro, 2019).

\subsection{Pesagem externa do produto com dados em planilhas}

No método utilizado por Palacin et al. (2005), a massa do produto é medida em um ambiente externo ao secador e as variações da massa são registradas em planilhas. Esse método pode acarretar perdas de massa do produto na retirada desse do sistema e, portanto, ocasionar erros ao determinar-se as taxas de secagem.

\subsection{Sistema automático utilizando-se uma equação linear} de massa $x$ tensão

O sistema desenvolvido por Monte et al. (2008) é capaz de relacionar a massa com a tensão lida por um módulo de aquisição acoplado às células de carga, sem a necessidade da retirada do produto do sistema. Esse método funciona muito bem para obtenção da massa com um fluxo de ar nulo. Entretanto, ao ser inserido um fluxo de ar de $0,27 m \cdot s^{-1}$, por exemplo, a curva obtida apresenta erros expressivos com relação aos valores estimados.

\subsection{Sistema de pesagem com equações diferentes para cada} fluxo de ar

No método desenvolvido por Rodrigues et al. (2011) foram utilizadas equações de primeiro grau para descrever a massa em função da tensão. Como foi utilizado fluxo de ar aquecido para realizar a operação de secagem, houve a necessidade de realizar calibrações no sistema de pesagem para cada fluxo utilizado. A Tabela 1 apresenta os coeficientes de calibração obtidos para três fluxos distintos, em diferentes temperaturas de secagem. Os resultados obtidos foram muito bons, porém esse método resulta em pequenos erros na obtenção das massas, mesmo com a curva correspondente, sendo os erros maiores em fluxos com maiores velocidades. Além disso, caso haja necessidade de se operar com um fluxo de ar de secagem diferente dos apresentados, haverá a necessidade de uma nova calibração para esse fluxo.

Tabela 1. Equações de calibração das células de carga para fluxos de ar de secagem de 0,30, 0,35 e $0,45 \mathrm{~m} / \mathrm{s}$.

\begin{tabular}{ccc}
\hline $\begin{array}{c}\text { Velocidade do } \\
\text { fluxo de ar } \\
\left(m \cdot s^{-1}\right)\end{array}$ & $\begin{array}{c}\text { Equação ajustada } \\
\text { e coeficiente de } \\
\text { determinação }\left(R^{2}\right)\end{array}$ & $\begin{array}{c}\text { Erro } \\
\text { padrão } \\
(\mathrm{g})\end{array}$ \\
\hline 0,30 & $\mathrm{~m}=559,12 \mathrm{Vs}+0,634 \mathrm{~T}-8595,6$ \\
$R^{2}=0,9998$ & 9,16 \\
\hline 0,35 & $\mathrm{~m}=552,10 \mathrm{Vs}+0,905 \mathrm{~T}-9042,8$ \\
$R^{2}=0,9992$ & 20,11 \\
\hline 0,45 & $\mathrm{~m}=559,12 \mathrm{Vs}+0,634 \mathrm{~T}-8595,6$ \\
$R^{2}=0,9985$ & 27,67 \\
\hline \multicolumn{3}{c}{ Fonte: Rodrigues et al. $(2011)$ - Adaptada }
\end{tabular}

3.4 Sistema automático com desligamento do sistema de ventilação na aquisição de massa

A calibração estática das células de carga foi feita com o sistema de ventilação desligado, sem a influência do fluxo do ar de secagem. Após realizar-se a calibração, foi obtida uma relação linear entre massa $(\mathrm{g})$ e tensão $(\mathrm{mV})$. A curva obtida para uma das bandejas do secador está na Figura 2. Os resultados dessa calibração foram muito bons, com o valor de $R^{2}=1$.

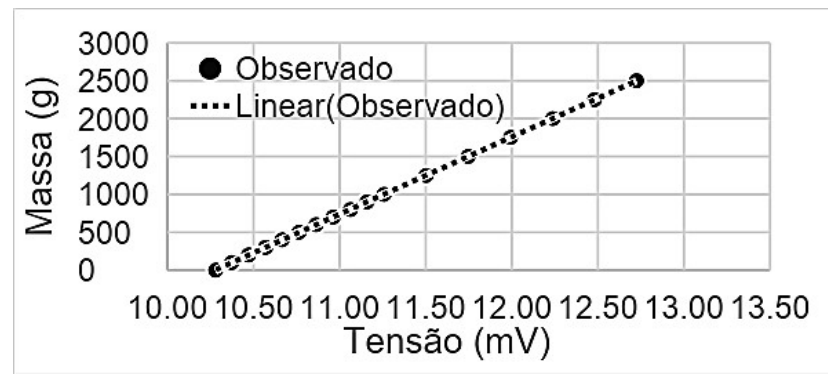

Figura 2. Correlação da massa x tensão nas células de carga (Fonte: Carneiro (2019))

Para variadas massas, a influência do fluxo de ar sobre a tensão nas células não se manteve constante, dificultando a obtenção de uma equação que descrevesse a massa em função da tensão e do fluxo de ar como pode ser observado na Figura 3.

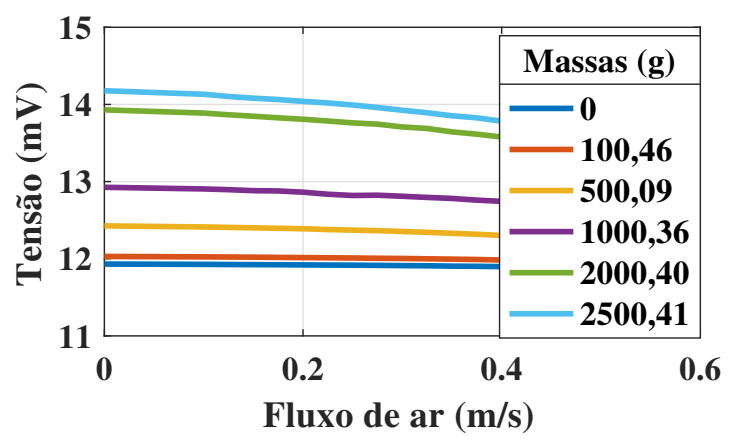

Figura 3. Curvas de variação da tensão em função do fluxo de ar para várias massas (Fonte: Carneiro (2019))

Portanto, a aquisição dos valores de tensão para o cálculo da massa foi feita desligando-se o sistema de ventilação a cada 2 minutos e, em seguida, realizando-se a aquisição dos dados de massa. O sistema de ventilação era religado após $17 \mathrm{~s}$, tempo necessário para que o sistema de pesagem se estabilizasse e registrasse a massa atual. Esse comportamento pode ser visto na Figura 4.

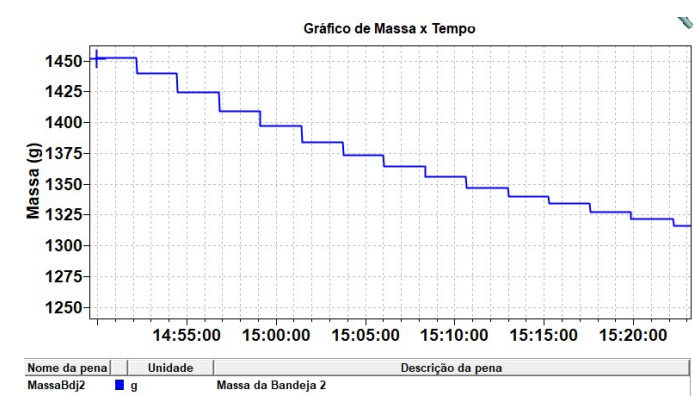

Figura 4. Comportamento do sistema de aquisição de massa (Fonte: Carneiro (2019))

A utilização desse método descarta a necessidade de várias curvas de massa x tensão para variados fluxos de ar, já 
que a aquisição de dados de massa é feita com o sistema de ventilação desligado. Assim a equação obtida para a velocidade nula pode ser utilizada durante a secagem. No entanto, esse método causa oscilações nos parâmetros de secagem como a temperatura e o fluxo de ar. A Figura 5 apresenta o controle de temperatura com a utilização desse procedimento. Há um rápido aumento de temperatura a cada aquisição do valor da massa do produto assim que o sistema de ventilação é desligado e uma queda após se religar o referido sistema.

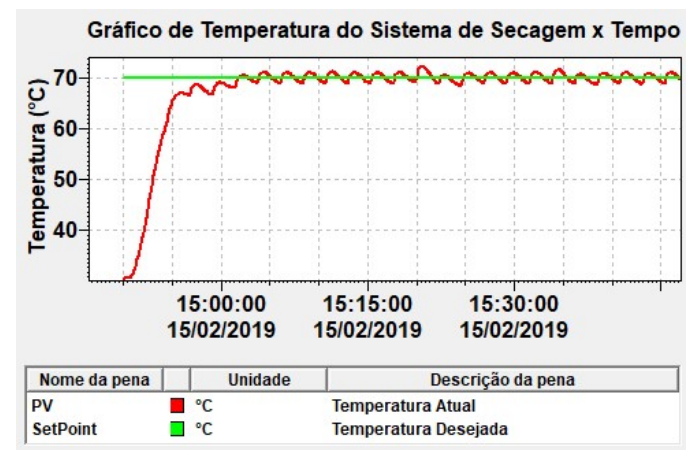

Figura 5. Atuação do controle de temperatura durante a secagem (Fonte: Carneiro (2019))

Na Figura 6 é possível perceber as oscilações no fluxo de ar nos intervalos de aquisição de dados.

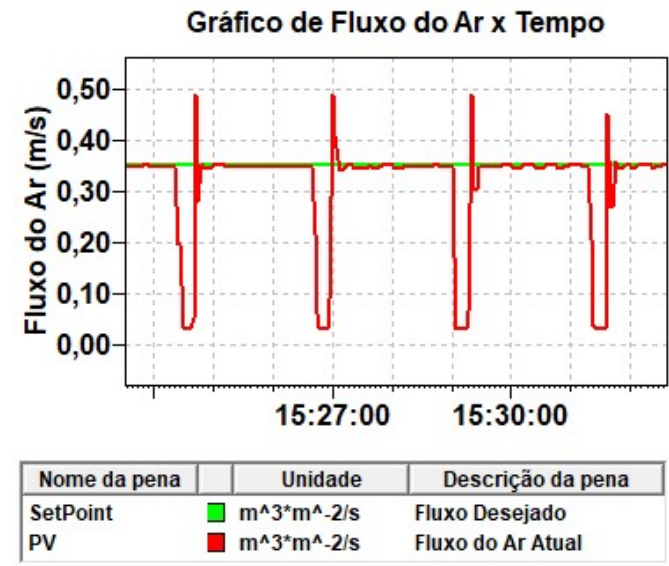

Figura 6. Controle de fluxo de ar durante a secagem (Fonte: Carneiro (2019))

As oscilações nos valores de velocidade ocorrem porque a calibração do sistema de pesagem foi feita para velocidades nulas do ar de secagem. Portanto, o sistema de ventilação foi desligado nos momentos de aquisição da massa. Apesar dessas variações, o controle proporcional-integral implementado foi capaz de retomar o valor desejado de fluxo do ar entre os intervalos de aquisição.

\section{METODOLOGIA}

\subsection{Sistema automático com a utilização de uma rede neural}

O objetivo desse sistema é obter o valor da massa em função da tensão lida pela célula de carga e do fluxo de ar desejado a partir do treinamento de uma rede neural. Trata-se de uma abordagem nova. A base de dados utilizada para o treinamento desta rede foi obtida com o protótipo do secador aqui apresentado. Os valores de tensão medidos são para massas fixas conhecidas, variando-se o fluxo do ar de secagem em uma faixa pré-determinada.

O desenvolvimento da RNA foi dividido da seguinte forma:

- Seleção e configuração de dispositivos de leitura de controle de velocidade;

- Seleção e configuração de dispositivos de leitura de tensão;

- Medição das massas em uma balança de referência;

- Desenvolvimento de um algoritmo de leitura dos dados;

- Tratamento dos dados de tensão e velocidade obtidos para diversas massas conhecidas inseridas no sistema de secagem;

- Desenvolvimento de uma rede neural para correlacionar velocidade e tensão com a massa de produto;

- Validação e Testes da rede neural.

\subsection{Medição e controle do fluxo de ar de secagem}

Para a medição do fluxo de ar de secagem, foi utilizado um transmissor de temperatura e velocidade do ar apresentado na Figura 7a com o sensor do tipo anemômetro de fio quente (Figura 7b) .
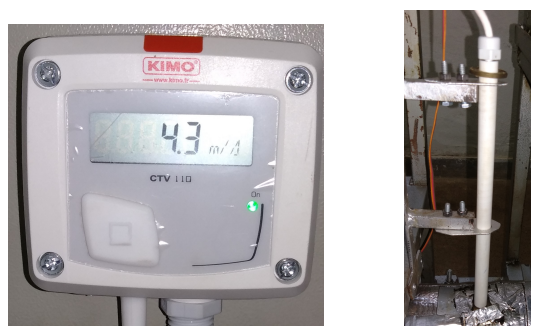

Figura 7. (a) Transmissor de velocidade;(b) Fixação do anemômetro de fio quente

O controle da velocidade do ventilador é feito por um inversor de frequência que possui um regulador PID ajustável. O setpoint do fluxo de ar requerido é fornecido pelo usuário por meio do sistema de supervisão ou pela IHM do inversor de frequência. A ação de controle é dada em função do erro entre fluxo lido e desejado.

\subsection{Medição das tensões das células de carga}

A fixação das células de carga do tipo S na planta está retratada na Figura 8a.

Foi feita a conexão das células a uma caixa de junção, como visto na Figura 8b, que consiste em um circuito que une os sinais das células de carga como um único sinal (Technologies, 2012). O uso da junção diminui a quantidade de canais utilizados em um módulo de aquisição, usado para converter os sinais das células de carga em sinal serial MODBUS.

\subsection{Aquisição de dados das massas}

Uma vez estabelecidos os dispositivos de leitura das tensões nas células de carga e do fluxo do ar de secagem, 

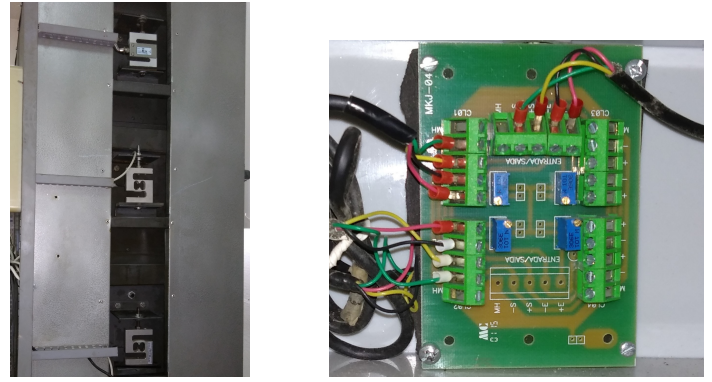

Figura 8. (a) Fixação das células de carga; (b) Caixa de junção das células de carga

foram levantados diversos valores de tensão para alguns fluxos de ar de secagem. Foi utilizado milho seco como produto a ser pesado. Foram inseridas massas conhecidas de milho em uma das bandejas, variando-se seus valores da seguinte forma: (i) de 100 em 100 gramas até completar-se $1.000 \mathrm{~g}$; (ii) em seguida, os intervalos foram de $250 \mathrm{~g}$ até completar-se $3000 \mathrm{~g}$, que corresponde ao valor máximo de capacidade do sistema de pesagem. A cada massa inserida, foi executado um algoritmo de aquisição de dados no sistema de supervisão.

Nesse algoritmo, a massa permanece constante e estabelecese que o fluxo de ar varia a cada 20 segundos em uma faixa de 0,1 até $0,6 \mathrm{~m} \cdot \mathrm{s}^{-1}$, com um intervalo de $0,025 \mathrm{~m} \cdot \mathrm{s}^{-1}$ entre as variações. $O$ valor de tensão correspondente foi registrado em um banco de dados após o fluxo de ar lido ser muito próximo ao desejado, garantindo leituras da tensão para valores fixos do fluxo de ar.

Esse teste foi realizado para todas as massas definidas, com o fluxo de ar variando no sentido crescente e decrescente, de modo que a cada 13,33 minutos, os dados de tensão e velocidade para a massa inserida foran exportados para uma planilha, e então uma nova massa foi inserida, repetindo esse procedimento até a massa de $3000 \mathrm{~g}$.

Após esses testes, os dados obtidos foram tratados, retirando-se a média aritmética dos valores de tensão nos dois sentidos e todas as informações foram dispostas em forma de uma tabela. Nesta tabela, os fluxos de ar, as tensões e as massas foram dispostas em coluna, para serem posteriormente utilizadas pela rede neural.

\subsection{Desenvolvimento da rede neural}

Uma vez que foram adquiridos os dados de tensão, fluxo de ar e massa, tornou-se possível a utilização desses valores para treinamento supervisionado de uma rede neural do tipo percéptrons de múltiplas camadas, a fim de se encontrar um regressor que calculasse a massa do produto conforme a tensão e o fluxo de ar. Para tanto, foi utilizado o toolbox nftools do software Matlabß. Foram feitos testes com números de neurônios diferentes, buscando uma estrutura de rede ótima que apresentasse uma capacidade de generalização elevada.

Dessa forma, a rede foi composta por quatro neurônios e o algoritmo utilizado para treinamento foi o de Levenberg Marquardt, com duas camadas de rede, uma oculta, com função de ativação tangente hiperbólica e uma de saída com função de ativação linear, tal como pode ser visto na Figura 9 .

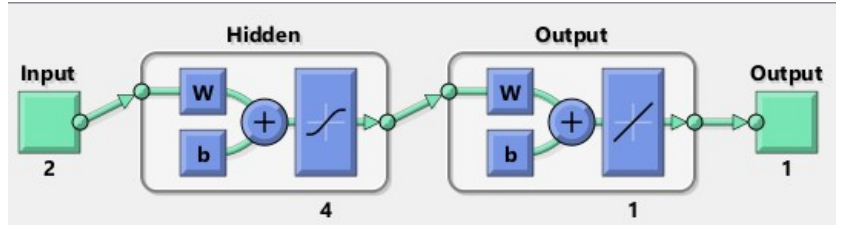

Figura 9. Layout da rede neural definida para solução do problema proposto

Após o treinamento da rede neural e posterior validação, foram obtidos os pesos e bias que realizam o mapeamento entre as duas entradas (tensão e fluxo) e a saída (massa) do problema aqui proposto.

\section{RESULTADOS OBTIDOS}

O método utilizado para aquisição das tensões possibilitou os testes devidos com a rede neural, e como pode ser observado na Figura 10, os valores de massa obtidos pela rede foram muito próximos aos valores reais das massas, para o conjunto de fluxos de ar e tensões lidos.

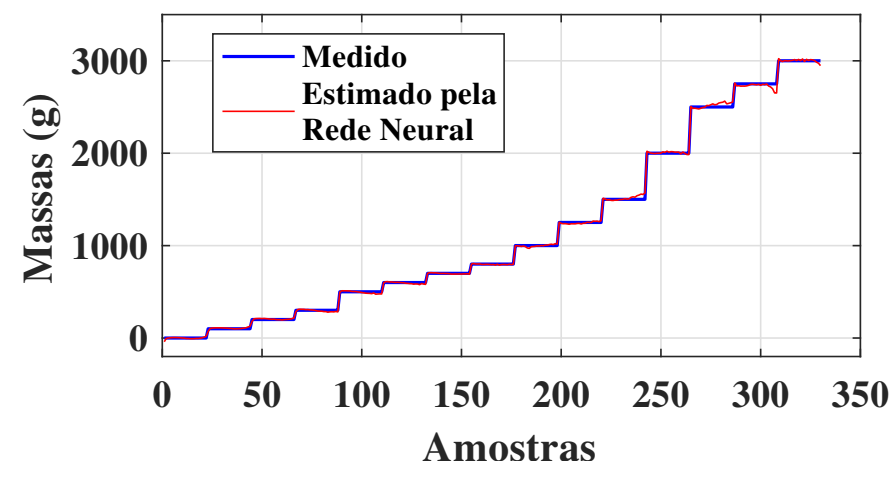

Figura 10. Saídas em massa para entradas de tensões e fluxos de ar

Na Tabela 2, é possível ver os valores de massa obtidos para o conjunto de tensões e fluxo de ar no teste com uma massa de $900,29 \mathrm{~g}$, que propositalmente não foi utilizada durante o treinamento da rede neural.

Tabela 2. Saídas da rede neural para uma massa de $900,29 \mathrm{~g}$

\begin{tabular}{ccccc}
\hline $\begin{array}{c}\text { Fluxo } \\
\text { de ar } \\
\left(m \cdot s^{-1}\right)\end{array}$ & $\begin{array}{c}\text { Tensão } \\
(\mathbf{m V})\end{array}$ & $\begin{array}{c}\text { Massa de } \\
\text { Produto } \\
\text { Estimada } \\
\mathbf{( g )}\end{array}$ & $\begin{array}{c}\text { Resíduo } \\
\mathbf{( g )}\end{array}$ & $\begin{array}{c}\text { Erro } \\
\text { Relativo } \\
\mathbf{( \% )}\end{array}$ \\
\hline 0 & 12,825 & 897,521 & 2,769 & 0,308 \\
\hline 0,1 & 12,812 & 907,126 & $-6,836$ & 0,759 \\
\hline 0,15 & 12,788 & 897,639 & 2,651 & 0,294 \\
\hline 0,2 & 12,769 & 896,124 & 4,166 & 0,463 \\
\hline 0,25 & 12,747 & 895,515 & 4,775 & 0,530 \\
\hline 0,3 & 12,717 & 891,287 & 9,003 & 1,000 \\
\hline 0,35 & 12,689 & 894,695 & 5,595 & 0,621 \\
\hline 0,4 & 12,649 & 891,026 & 9,264 & 1,029 \\
\hline 0,45 & 12,61 & 894,651 & 5,639 & 0,626 \\
\hline 0,5 & 12,564 & 895,524 & 4,766 & 0,529 \\
\hline 0,55 & 12,521 & 905,357 & $-5,067$ & 0,563 \\
\hline 0,6 & 12,466 & 904,57 & $-4,28$ & 0,475 \\
\hline
\end{tabular}

Os valores obtidos de erro relativo mostraram que a rede poderia ser utilizada para uma massa diferente da utilizada 
durante o treinamento, desde que pertencente ao intervalo de 0 a $3000 \mathrm{~g}$, e para fluxos de ar na faixa pré-estabelecida, atestando a boa capacidade de generalização da rede.

\section{CONCLUSÃO}

A secagem é a remoção parcial da água contida nos produtos agrícolas. Um secador automático de grãos é um equipamento utilizado para esse fim. Neste trabalho, apresentou-se uma nova forma de correção para o sistema de pesagem do secador de produtos agrícolas baseado em Redes Neurais Artificiais. A rede treinada mostrou-se como uma solução muito eficaz para o problema das medições de massa do produto para diferentes fluxos de ar de secagem.

Para novos trabalhos, deve ser analisado como esta estrutura treinada de rede neural comporta-se para medições de massa ao longo do processo da secagem, ou seja, de forma online. Além de haver constante perda de massa de produto em decorrência do processo de secagem, podem ocorrer oscilações no fluxo de ar. Portanto, a rede deve ser capaz de fornecer o valor correto da massa atual do produto mesmo com a influência de ambos fatores. Além disso, essa técnica deverá ser testada para produtos diferentes do milho, a fim de avaliar a qualidade desse método para a secagem de outros grãos.

\section{REFERÊNCIAS}

Carneiro, D.d.S. (2019). Aprimoramento de um sistema automático de secagem de produtos agrícolas para utilização como planta didática no curso de automação industrial no ifmg - campus ouro preto. Monografia apresentada ao Departamento de Controle e Automação e Técnicas Fundamentais, UFOP, 2019.

Corrêa, P.C., Oliveira, G.H.H., Botelho, F.M., Goneli, A.L.D., and Carvalho, F.M. (2010). Modelagem matemática e determinação das propriedades termodinâmicas do café (coffea arabica l.) durante o processo de secagem.

Monte, J.E.C., Martins, J.H., Lopes, D.d.C., Monteiro, P.M.d.B., and Pinto, P.R. (2008). Sistema automático para secagem de produtos agrícolas em camada fina.

Palacin, J.J.F., de Lacerda Filho, A.F., Cecon, P.R., and Montes, E.J.M. (2005). Determinações das curvas de secagem de milho nas espigas (zea mays l.). Engenharia na Agricultura, Viçosa, 13(4), 300-313.

Rodrigues, C.L.C., Martins, J.H., Monteiro, P.M.d.B., Melo, E.d.C., and Fortes, M. (2011). Sistema automático de pesagem para determinação da curva de secagem de grãos em camada fina. In VI Congresso Ibérico de AgroEngenharia, 2011. Universidade de Évora., Anais do VI Congresso Ibérico de AgroEngenharia, Évora. Portugal.

SILVA, E., OLIVEIRA, J., MACHADO, A., and DE OLIVEIRA, C. (2015). R. secagem de grãos e frutas: Revisão bibliográfica. Revista Brasileira de Agrotecnologia, 5(1), 19-23.

SILVA, J.d.S.e. (2001). Secagem e armazenamento de café: tecnologias e custos. Universidade Federal de Viçosa.

Technologies, A. (2012). Problemas em aplicações de célula de carga com a solução de conectividade sem fio da agilent. Available at: http://literature.cdn.keysight.com/litweb/pdf/ 5990-9941PTBR.pdf (acessed 24 april 2019). 